\title{
Ichthyosis-prematurity syndrome
}

INSERM

\section{Source}

INSERM. (1999). Orphanet: an online rare disease and orphan drug data base. Ichthyosisprematurity syndrome. ORPHA:88621

Ichthyosis prematurity syndrome is a rare, syndromic congenital ichthyosis characterized by premature birth (at gestational weeks 30-32, in general) in addition to thick, caseous and desquamating epidermis, neonatal respiratory asphyxia, and persistent eosinophilia. After the perinatal period, a spontaneous improvement in the health of affected patients is observed and skin features (vernix caseosa-like scale) evolve into a mild presentation of flat follicular hyperkeratosis with atopy. 